\title{
Thyroid disorders in women with dysfunctional uterine bleeding
}

\author{
Subedi $\mathrm{S}^{1}$, Banerjee B ${ }^{1}$, C.Manisha ${ }^{1}$ \\ ${ }^{l}$ Department of Obstetrics and Gynecology, Nobel Medical College, Biratnagar, Nepal
}

\section{Keywords: \\ Hypothyroidism; \\ Hyperthyroidism; \\ Thyroid; \\ Menorrhagia}

\begin{abstract}
Background: Thyroid hormones play a key role in the menstrual and reproductive function of women . It is recognized universally that menstrual disturbances may accompany clinical alteration in thyroid function and every clinician has encountered altered menstrual pattern among women suffering from thyroid disorders. The aim of this study was to find the incidence of thyroid disorders in Dysfunctional uterine bleeding and its correlation with menstrual patterns.
\end{abstract}

Materials and Methods: A hospital based cross-sectional study including 75 cases with dysfunctional uterine bleeding attending the OPD of Nobel Medical College, where incidence of thyroid disorder was evaluated along with its correlation with menstrual patterns and histopathology.

Results: The incidence of Gynecological OPD attendance due to abnormal uterine bleeding was 3\%.and the incidence of thyroid dysfunction was $10.6 \%$ with hypothyroidism being the commonest. (9.3\%). The commonest menstrual pattern found was menorrhagia/polymenorrhoea in 8 percent.

Conclusion: Prevalence of hypothyroidism was more common in DUB. Thus every woman with menstrual irregularities should undergo thyroid assessment and this will ultimately avoid unnecessary intervention like misuse of hormonal treatment and hysterectomy.

\section{INTRODUCTION}

Dysfunctional uterine bleeding (DUB) is a diagnosis of exclusion. It is one of the most frequently encountered conditions in gynecology and is defined as abnormal bleeding from the uterus in the absence of any organic disease of the genital tract. It has also been defined as heavy and or irregular menstruation without structural pathology, pregnancy and general bleeding disorders. ${ }^{1}$ In gynecology,

\section{Correspondence:}

Dr.Shanti Subedi, MBBS, MD

Assistant Professor, Department of Obstetrics and Gynecology

Nobel Medical College, Biratnagar, Nepal

E-mail-subedi007@gmail.com more than $20 \%$ of women present with DUB. ${ }^{2}$ Abnormal uterine bleeding includes both DUB and bleeding from structural cause. The underlying cause of DUB is still uncertain and varied, but in most cases it is associated with anovulation. This form of DUB is mostly seen in adolescent and perimenopausal women. Defective corpus luteum following ovulation results in Ovulatory DUB.

Thyroid hormones play a key role in the menstrual and reproductive function of women. It is recognized universally that menstrual disturbances may accompany 
clinical alteration in thyroid function and every clinician has encountered altered menstrual pattern among women suffering from thyroid disorders. ${ }^{3}$ Intact hypothalamus, pituitary and thyroid gland axis is needed for normal menstruation. Hypothyroidism usually causes menorrhagia and hyperthyroidism causes oligomenorrhoea. ${ }^{3}$ This study was conducted to find the incidence of thyroid disorders in DUB patients and secondarily to study the menstrual pattern in thyroid disorders.

\section{MATERIALS AND METHODS}

A hospital based cross-sectional study was carried out in the department of Obstetrics and Gynecology, Nobel Medical College and Teaching hospital for a period of one year (June 2014-May 2015). Prior to the study, ethical clearance was obtained. Women in reproductive age group with the complaints of menstrual irregularities attending to the outpatient of gynecology were taken in the study, which included a total of 75 cases out of 2500 outpatients. Patients with pregnancy related bleeding; any organic causes of the uterus, bleeding diathesis, IUCD use and known hypo/ hyperthyroid patients already on drugs were excluded from the study. The study protocol included a thorough history taking according to the predesigned questionnaire, BMI was calculated by standard formula, clinical examination including abdominal, vaginal and thyroid gland evaluation, routine blood investigation, trans-abdominal USG, endometrial biopsy and serum T3, T4 and TSH.

Following reference values were taken as normal:

\begin{tabular}{|c|c|c|}
\hline 1. & Serum T3- & $0.77-1.98 \mathrm{ng} / \mathrm{ml}$ \\
\hline 2. & Serum T4- & $6.09-12.23 \mathrm{ug} / \mathrm{ml}$ \\
\hline 3 & Serum TSH- & $0.34-5.12 \mathrm{uIU} / \mathrm{ml}$ \\
\hline
\end{tabular}

Statistical analsysis was performed using SPSS vs. 16 wherever applicable.

\section{RESULTS}

A total of 75 patients visited with complaints of menorrhagia in the outpatient department of gynecology. Regarding age distribution of the patients, majority of the patients $(n=40$; $53.33 \%$ ) were in the age group of 35-45 years, followed by 25 patients $(33.33 \%)$ were between $25-34$ years and 10 patients $(13.33 \%)$ were $15-24$ years. Basic mass index (BMI) was calculated in the study population. Forty patients (60\%) had normal BMI whereas 25 patients $(33.33 \%)$ were overweight and 5 patients (6.66) were obese.

Out of these patients, 4 patients $(5.33 \%)$ were smoker but none were alcoholic. Eight patients were known case of Diabetes Mellitus (10.66\%) and 12 (16\%) were hypertensive.
Table: 1 Distribution of patients according to thyroid status in relation to type of bleeding pattern

\begin{tabular}{lcc}
\hline Type of bleeding pattern & Hypothyroidism & Hyperthyroidism \\
\hline $\begin{array}{l}\text { Menorrhagia/Polymen- } \\
\text { orrhoea }\end{array}$ & 6 & 0 \\
$\begin{array}{l}\text { Oligomenorrhoea/ } \\
\text { Hypomenorrhoea }\end{array}$ & 1 & 1
\end{tabular}

Thyroid disorders were identified in $8(10.66 \%)$ patients. Detail findings and type of bleeding pattern is shown in table 1 . The most common bleeding pattern associated with hypothyroid patients was polymenorrhoea and menorrhagia in 6 of the patients. Among these patients with thyroid disorder no endometrial pathology was detected.

\section{DISCUSSION}

Dysfunctional uterine bleeding is as difficult to define as it is to cure affecting $10-15 \%$ of all gynecological patients. Fortunately, scientific research has been able to demonstrate the complex cyclical interplay between hormones and uterus that leads to visible loss of endometrial tissue and blood called menstruation. The social and economic cost of DUB is considerable. ${ }^{4}$ About one third of the hysterectomies are carried out for menstrual disturbances alone..$^{5}$ Thyroid disorders in general and hypothyroidism in particular is extremely common in women. Nevertheless, events from menarche, pubertal growth, reproductive years, postpartum period and postmenopausal years are profoundly influenced by the thyroid status of the women.

Regarding age distribution of DUB patients in this study, $53.33 \%$ were found between the ages of 35-45 years followed by $33.33 \%$ between the age group of 25-34 years and it is similar to the study done by Sangeetha Pahwa et al, where $42 \%$ were in the age group of 31-40 years, 6 and the highest incidence amongst the age group between 35-45 years in the study done by K. Padmaleela et al. ${ }^{7}$ Das and Chugh reported the highest incidence of $32.5 \%$ in $41-50$ years of age and $^{8} 32.8 \%$ in the age group of 31-40 years of age in the study done by Narula et al. ${ }^{9}$

In this study, 9.3\% of the DUB cases were found to be associated with hypothyroidism, $1.3 \%$ hyperthyroidism and $89.3 \%$ were euthyroid. In the study done by Wilansky et al, ${ }^{10} 22 \%$ were found to be hypothyroid which is similar to the study done by Sangeetha Pahwa et al, where the incidence of hypothyroidism was $22 \%$ out of 100 cases. $^{6}$ K. Padmaleela et $\mathrm{al}^{7}$ found an incidence of $18.1 \%$ of hypothyroidism and the study done by $\mathrm{T}$ Kaur et al the incidence of hypothyroidism was 14 percent. $^{3}$

Regarding menstrual pattern in relation to thyroid status, for the convenience it is divided into menorrhagia, polymenorrhoea as one entity and oligomenorrhoea and hypomenorrhea as another entity and it was found that 6 of 
them had menorrhagia and 2 with oligomenorrhoea. One of our patients with hypothyroidism had oligomenorrhoea which is not a usual scenario but it has been said that if the disease is a long standing it can cause the same. In the study done by Sangeetha Pahwa et al, the commonest complaint was menorrhagia in $50 \%$ of the total cases, followed by polymenorrhoea in $19 \%{ }^{6}$ This is similar to the study conducted by K. Padmaleela et al, where menorrhagia was the commonest complaint in 50\%. ${ }^{7}$ Kaur T et al demonstrated that out of 14 hypothyroid cases, 9 had menorrhagia, 3 had oligomenorrhoea and 1 with hyperthyroid was found to have hypermenorrhagia. ${ }^{3}$

Ingbar et al and Pearce et al in their study said that menstrual irregularity is significantly more common in hypo or hyperthyroidism as compared to control cases. ${ }^{11}$ In hypothyroidism, menorrhagia/polymenorhoa is common and hypomenorrhoea is found in hyperthyroidism, which was also confirmed by Pushpa Sirichand. ${ }^{12}$ According to Redmond, any type of menstrual irregularity can occur with either hypo or hyperthyroidism. ${ }^{13}$

\section{CONCLUSION}

Prevalence of hypothyroidism was more common in DUB. Thus every woman with menstrual irregularities should undergo thyroid assessment and this will ultimately avoid unnecessary intervention like misuse of hormonal treatment and hysterectomy.

\section{REFERENCES}

1. Lumsden M, Normal J. Menstruation and Menstrual abnormality. In: Shaw RW, Soutter WP, Stanton SL (eds) Gynecology,2nd edn. London, Churchill Livingstone,1997.p421-39.

2. Nesse R. Abnormal vaginal bleeding in Perimenopausal women. Am Family Physician 1989;40:185-92. Crossref

3. Kaur T, Aseeja V, Sharma S. Thyroid Dysfunction in Dysfunctional uterine Bleeding. Webmed Central obstetrics and Gynecology.2011;2:WMC002235.

4. G Dangal. Dysfunctional uterine bleeding and its management strategy. J Nepal Med Assoc 2003;40:98-106.

5. Coulter A, Mc Pherson K, Vessey M. Do British Women to many or too few hysterectomies? Soc Sci Med 1988;27:987-94. Crossref

6. Pahwa, Kaur, Ga. Thyroid Dysfunction in Dysfunctional Uterine Bleeding. JARBS. 2013;5:78-83.

7. K. Padmaleela, Vimala Thomas, Lavanya K.M et al.Thyroid dysfunction in Dysfunctional Uterine Bleeding among reproductive age group women- A cross -sectional study in a tertiary care hospital in Andhra Pradesh, India.Int J Med Pharm Sci 2013;04:41-6.
8. Dass A, Chugh S . Dysfunctional uterine bleeding. J Obstet Gynecol of India $1964 ; 348-53$.

9. Narula ER. Menstrual Irregularities. J Obstet \& Gynecol India 1967;17:164.

10. Wilansky DL, Berrnard G. Early hypothyroidism in patients with menorrhagia. Am J Obst Gynae 1989; 160:673-77. Crossref

11. Ingbar SH, Braveman LE. Thyroid Dysfunction- Clinical Manifestations.In: Werner Sc, 5th edn Philadelphia:Lippincott Williams\&Wilkins;1986.p626.

12. Sirichand P.Impaired Thyroid Functions in Patients with Menstrual Disturbances. (An experience of a private clinic). World Applied Sciences Journal 2009;7:538-42.

13. Redmond GP. Postpartum Thyroiditis.Thyroid 2004;14(S):5-15. 